\title{
Prediksi Ukuran Risiko Agregat Klaim Berbasis Copula pada Model Autoregressive Conditional Amount (ACA)
}

\author{
Dedy Irawan Prihandoko ${ }^{1}$, Khreshna I.A. Syuhada ${ }^{2}$ \\ ${ }^{1}$ Magister Aktuaria, FMIPA, Institut Teknologi Bandung, \\ ${ }^{1}$ dirawanprihandoko@gmail.com \\ ${ }^{2}$ KK Statistika, FMIPA, Institut Teknologi Bandung,
}

${ }^{2}$ khreshna@math.itb.ac.id

\begin{abstract}
Abstrak
Industri asuransi merupakan industri yang berkaitan langsung dengan risiko. Risiko yang terjadi diakibatkan oleh besar klaim yang harus dibayarkan perusahaan asuransi. Dalam praktiknya, besar klaim berasal dari berbagai sumber bisnis perusahaan sehingga dipandang sebagai risiko agregat. Pada artikel ini, risiko agregat dikonstruksi dari jumlahan dua besar klaim suatu lini bisnis yang saling bergantung. Kebergantungan antar besar klaim dapat direpresentasikan melalui Copula. Copula yang digunakan pada artikel ini adalah Copula Clayton, Copula Frank, dan Copula Gumbel. Kemudian besar klaim harus dapat dimodelkan dan diprediksi nilainya sehingga perusahaan dapat melakukan strategi agar tidak terjadi kebangkrutan. Model Autoregressive Conditional Amount (ACA) merupakan model yang dapat digunakan untuk memodelkan besar klaim dengan memanfaatkan data besar klaim masa lalu. Selanjutnya metode Value-at-Risk (VaR)dapat digunakan untuk memprediksi nilai besar klaim yang akan datang dengan tingkat kepercayaan tertentu. Dengan memanfaatkan model kebergantungan Copula, model klaim ACA dan metode Value-at-Risk maka didapatkan prediksi VaR untuk risiko agregat. Hasil prediksinya adalah sebesar 13.0171 dengan model kebergantungan terbaik menggunakan Copula Gumbel.

Kata kunci : risiko agregat, copula, besar klaim, Autoregressive Conditional Amount, prediksi Value-at-Risk.
\end{abstract}

2000 Mathematics Subject Classification: 62P05 Received: 2019-08-31, Revised: 2020-01-30 accepted: 2020-02-05. 


\begin{abstract}
The insurance industry is an industry directly related to risk. The risk that occurs due to the claim severity that must be paid by an insurance company. In practice, claim severity come from various sources of the company's business so that it is seen as an aggregate risk. In this article, aggregate risk is constructed from the sum of the two claim severities of dependent line of business. Dependence between claim severities can be represented through Copula. Copula used in this article are Copula Clayton, Frank Copula, and Copula Gumbel. Then, claim severity must be modeled and predictable in value so the company can carry out a strategy to prevent bankruptcy. TheAutoregressive Conditional Amount (ACA) model is a model that can be used to model claim severity by utilizing data from the past. Furthermore, the Value-at-Risk (VaR) method can be used to predict the value of future claims with a certain level of confidence. By utilizing the Copula dependency model, the ACA claim model (1,1) and the Value-at-Risk method, the VaR prediction for aggregate risk is obtained. The prediction result is 13 with the best dependency model using Copula Gumbel.

Keywords: aggregate risk, copula, claim severity, Autoregressive Conditional Amount, prediction of Value-at-Risk.
\end{abstract}

\title{
1. Pendahuluan
}

Risiko secara umum didefinisikan sebagai potensi terjadinya suatu peristiwa, baik yang diperkirakan maupun tidak dapat diperkirakan dan dapat menimbulkan kerugian. Risiko yang merugikan tentu diharapkan dapat diminimalisir keberadaannya. Risiko dapat terjadi di berbagai bidang antara lain bidang pasar modal pada penelitian Wong et al.,[15], bidang konstruksi pada penelitian Iqbal et al.,[7], dan bidang asuransi pada penelitian Araichi et al., [2]. Pada penelitian-penelitian tersebut hanya menganalisa risiko tunggal saja. Namun dalam praktiknya, risiko yang terjadi tidak hanya melibatkan risiko tunggal saja, melainkan akan terdapat risiko agregat yang merupakan agregasi dari risiko-risiko yang mungkin terjadi. Penelitian tentang risiko agregat pernah dilakukan oleh Li et al.,[9] dan Venter [14] dengan risiko agregatnya berupa risiko kredit, risiko pasar, dan risiko operasional yang ada di bank. Risiko-risiko tersebut saling bergantung artinya terdapat kebergantungan antar peubah acak risikonya. Kebergantungan peubah acak dapat dilihat melalui sifat distribusi bersama. Namun tidak semua distribusi memiliki sifat distribusi bersama sehingga diperkenalkan model Copula sebagai alternatif untuk mengkonstruksi sifat distribusi bersama.

Asuransi merupakan salah satu instrumen keuangan yang berkaitan langsung dengan risiko. Jika dipandang dari sisi perusahaan, risiko dapat direpresentasikan sebagai besar klaim yang harus dibayarkan oleh perusahaan. Perusahaan harus dapat memodelkan besar klaim tersebut agar dapat memprediksi besar klaim yang akan terjadi di masa depan. Araichi et al [3] memperkenalkan suatu model yang dapat memodelkan besar klaim yaitu model Autoregressive Conditional Amount (ACA). Dalam perusahaan, besar klaim atau risiko dapat terjadi dari berbagai sumber bisnis sehingga dipandang sebagai risiko agregat. Data besar klaim pada artikel ini berasal dari pembayaran klaim perusahaan asuransi Danish Insurance.

Setelah besar klaim dapat dimodelkan maka besar klaim dapat diprediksi nilainya melalui ukuran risikonya. Ukuran risiko yang dapat digunakan adalah Value-at-Risk (VaR). Value-atRisk merupakan risiko atau kerugian maksimum yang dapat ditanggung pada tingkat kepercayaan tertentu. Penelitian tentang VaR pernah dilakukan oleh Rohmawati [13] dengan peubah 
acak risikonya tunggal. Dalam artikel ini peubah acak risikonya dipandang sebagai risiko agregat yang saling bergantung. Merujuk pada penelitian Li et al.,[9], pada artikel ini akan membahas tentang risiko agregat besar klaim yang mengikuti model ACA dengan masing-masing besar klaim saling bergantung dan akan diprediksi ukuran risiko Value-at-Risk secara agregat.

\section{Ukuran Risiko pada Model Klaim ACA $(1,1)$}

2.1. Model Klaim ACA (1,1). Risiko dalam bidang asuransi dapat dipandang sebagai akibat dari pembayaran klaim yang dilakukan oleh perusahaan asuransi. Besar klaim dapat dimodelkan menjadi suatu model stokastik ACA $(1,1)$ yang diperkenalkan oleh Araichi et al., [3]. Misalkan $X_{t}$ adalah peubah acak yang menyatakan besar klaim pada waktu $t$.

$$
X_{t}=\psi_{t} \epsilon_{t}
$$

dengan $\epsilon_{t}$ adalah inovasi yang berdistribusi Eksponensial atau Weibull di mana $\mathrm{E}\left(\epsilon_{t}\right)=1$. Kemudian $\psi_{t}$ adalah ekspektasi bersyarat untuk klaim yang secara umum dirumuskan sebagai berikut

$$
\psi_{t}=\mathrm{E}\left(X_{t} \mid X_{t-1}\right)=\gamma_{0}+\sum_{i=1}^{p} \gamma_{i} X_{t-i}+\sum_{j=1}^{q} \theta_{j} \psi_{t-j}
$$

Pada artikel ini model untuk besar klaim mengikuti $\mathrm{ACA}(1,1)$ dengan inovasi berdistribusi Weibull. Sehingga ekspektasi bersyarat menjadi

$$
\psi_{t}=\gamma_{0}+\gamma_{1} X_{t-1}+\theta_{1} \psi_{t-1}
$$

Parameter-parameter pada model ACA $(1,1)$ dapat ditaksir dengan menggunakan metode maksimum likelihood. Namun sebelumnya terlebih dahulu menentukan sifat distribusi bersyarat dari model $\operatorname{ACA}(1,1)$. Misalkan $\epsilon_{t} \sim$ Weibull $(\theta, \beta)$ dengan fungsi distribusi sebagai berikut

$$
F_{\epsilon_{t}}(a)=1-e^{-(a / \theta)^{\beta}}
$$

Kemudian fungsi peluangnya adalah

$$
f_{\epsilon_{t}}(a)=\frac{\beta}{a}\left(\frac{a}{\theta}\right)^{\beta} e^{-(a / \theta)^{\beta}}
$$

Ekspektasi dari distribusi Weibull adalah

$$
\mathrm{E}\left(\epsilon_{t}\right)=\theta \Gamma(1+1 / \beta)
$$

Karena pada model ACA $(1,1)$ mensyaratkan ekspektasi dari inovasi bernilai satu maka parameter $\theta=\frac{1}{\Gamma(1+1 / \beta)}$ Selanjutnya akan ditentukan distribusi bersyarat dari $X_{t}$. Menggunakan teknik sifat distribusi maka

$$
\begin{aligned}
F_{X_{t} \mid X_{t-1}}\left(x_{t}\right) & =\mathrm{P}\left(X_{t} \leq x_{t} \mid X_{t-1}\right) \\
& =1-e^{-\left(\frac{x_{t}}{\left(\gamma_{0}+\gamma_{1} x_{t-1}+\theta_{1} \psi_{t-1}\right) \theta}\right)^{\beta}}
\end{aligned}
$$

Selanjutnya fungsi peluang bersyaratnya adalah

$$
f_{X_{t} \mid X_{t-1}}\left(x_{t}\right)=\frac{\beta}{x_{t}}\left(\frac{x_{t} \Gamma(1+1 / \beta)}{\gamma_{0}+\gamma_{1} x_{t-1}+\theta_{1} \psi_{t-1}}\right)^{\beta} e^{-\left(\frac{x_{t} \Gamma(1+1 / \beta)}{\gamma_{0}+\gamma_{1} x_{t-1}+\theta_{1} \psi_{t-1}}\right)^{\beta}}
$$

Pada model ACA $(1,1)$ terdapat empat parameter yang harus diestimasi. Menggunakan metode maksimum likelihood dengan fungsi peluang pada persamaan (1) maka fungsi likelohood yang terbentuk adalah

$$
L\left(\gamma_{0}, \gamma_{1}, \theta_{1}, \beta\right)=\prod_{t=2}^{n} f_{X_{t} \mid X_{t-1}^{*}}\left(x_{t}\right)
$$


Kemudian fungsi loglikelihoodnya adalah

$$
l\left(\gamma_{0}, \gamma_{1}, \theta_{1}, \beta\right)=\sum_{t=2}^{n}\left[\beta \log \left(\frac{x_{t} \Gamma(1+1 / \beta)}{\gamma_{0}+\gamma_{1} x_{t-1}+\theta_{1} \psi_{t-1}}\right)+\log \left(\frac{\beta}{x_{t}}\right)-\left(\frac{x_{t} \Gamma(1+1 / \beta)}{\gamma_{0}+\gamma_{1} x_{t-1}+\theta_{1} \psi_{t-1}}\right)^{\beta}\right]
$$

Estimasi parameter-parameter dapat ditentukan jika fungsi loglikelihoodnya maksimum. Secara analitik mendapatkan estimasi tersebut sulit sehingga estimasi dilakukan secara numerik.

2.2. Ukuran Risiko Value-at-Risk (VaR). VaR dapat didefinisikan sebagai nilai risiko maksimum yang dapat ditoleransi pada tingkat kepercayaan sebesar $(1-\alpha)$ dengan $\alpha \in(0,1)$ (Rohmawati [13]). Misalkan $X_{t}$ adalah peubah acak yang menyatakan kerugian pada waktu $t$ dengan fungsi distribusi $F_{X_{t}}\left(x_{t}\right)$. Untuk mendapatkan nilai VaR sama saja dengan memprediksi nilai risiko waktu $t+1$ dari waktu $t$. Menurut Klugman[8], VaR juga dapat didefinisikan sebagai kuantil ke-1 $-\alpha$ dari distribusi kerugian yang secara matematis dapat dituliskan sebagai berikut

$$
\begin{aligned}
\mathrm{P}\left(X_{t+1} \leq \operatorname{VaR} \mid X_{t}\right) & =1-\alpha \\
F_{X_{t+1} \mid X_{t}}(\mathrm{VaR}) & =1-\alpha \\
\operatorname{VaR}_{1-\alpha}^{t+1}\left(X_{t}\right) & =F_{X_{t+1} \mid X_{t}}^{-1}(1-\alpha)
\end{aligned}
$$

Dengan kata lain VaR merupakan invers dari distribusi kerugian. Karena $X_{t}$ dimodelkan menggunakan model ACA(1,1) dengan inovasi berdistribusi Weibull maka VaR untuk besar klaim adalah

$$
\operatorname{VaR}_{1-\alpha}^{t+1}\left(X_{t}\right)=\psi_{t} F_{\epsilon_{t}}^{-1}(1-\alpha)
$$

Uji Keakuratan VaR. Pada uji keakuratan VaR dilakukan untuk menentukan model mana yang tepat dalam penentuan nilai VaR. Keakuratan tersebut dilihat melalui nilai Correct VaR. Correct VaR merupakan perbandingan banyaknya nilai kerugian yang lebih kecil dari nilai VaR pada tingkat kepercayaan tertentu dibandingkan dengan total data kerugian (Abdal [1]). Misalkan $I_{t+1}$ adalah peubah acak indikator

$$
I_{t+1}= \begin{cases}1 & , \quad x_{t+1} \leq \operatorname{VaR}_{1-\alpha}^{t+1}\left(X_{t}\right) \\ 0 & , \text { selainnya }\end{cases}
$$

Peubah acak $I_{t+1}$ dipandang memiliki distribusi Bernoulli dengan kejadian sukses adalah $x_{t+1} \leq \operatorname{VaR}_{1-\alpha}^{t+1}\left(X_{t}\right)$ dengan peluang $1-\alpha$ (McNeil et al.,[10]). Sehingga akurasi VaR diformulasikan dengan

$$
\text { Correct } \mathrm{VaR}=\frac{\sum_{i=1}^{N} I_{t+1}}{N} \approx 1-\alpha
$$

dengan $N$ adalah banyaknya data.

\section{Ukuran Risiko Agregat}

3.1. Agregat Value-at-Risk. Dalam praktiknya, risiko yang ditanggung berasal dari berbagai sumber penyebab sehingga terdapat risiko agregat yang merupakan jumlahan dari tiap risiko. Risiko agregat harus dapat ditentukan ukuran risikonya misalnya VaR. Menurut Li et al., [9], metode yang dapat digunakan untuk menentukan VaR untuk risiko agregat adalah metode variance-covariance. Pada metode ini didasarkan pada interaksi antar risiko yang dijelaskan melalui koefisien korelasinya. Misalkan $X_{1}, X_{2}, \cdots, X_{n}$ adalah peubah acak risiko yang terdiri dari $n$ risiko yang tidak saling bebas sehingga terdapat $\rho\left(X_{1}, X_{2}\right), \cdots, \rho\left(X_{n-1}, X_{n}\right)$. Kemudian risiko agregat yang terbentuk adalah

$$
S=X_{1}+X_{2}+\cdots+X_{n}
$$


Selanjutnya dengan metode variance-covariance, VaR untuk risiko agregat secara umum diformulasikan sebagai berikut

$$
\operatorname{Ag}-\operatorname{VaR}_{1-\alpha}(S)=\sqrt{\mathbf{A} \mathbf{B} \mathbf{A}^{T}}
$$

dengan

$$
\begin{array}{r}
\mathbf{A}=\left(\begin{array}{cccc}
\operatorname{VaR}\left(X_{1}\right) & \operatorname{VaR}\left(X_{2}\right) & \cdots & \left.\operatorname{VaR}\left(X_{n}\right)\right) \\
\mathbf{B} & \rho\left(X_{1}, X_{2}\right) & \cdots & \rho\left(X_{1}, X_{n}\right) \\
\rho\left(X_{1}, X_{2}\right) & 1 & \cdots & \rho\left(X_{2}, X_{n}\right) \\
\vdots & \vdots & \ddots & \vdots \\
\rho\left(X_{n}, X_{1}\right) & \cdots & \cdots & 1
\end{array}\right)
\end{array}
$$

Dalam artikel ini risiko agregat yang terbentuk berasal dari dua peubah acak stokastik, $X_{1}=X_{t}$ dan $X_{2}=Y_{t}$. Sehingga risiko agregatnya menjadi

$$
S_{t}=X_{t}+Y_{t}
$$

Kemudian agregat VaR, menurut Dowd[5] dan Corrigan et.al., [4] diformulasikan sebagai berikut

$$
\operatorname{Ag}-\operatorname{VaR}_{1-\alpha}^{t+1}\left(S_{t}\right)=\sqrt{\operatorname{VaR}\left(X_{t}\right)^{2}+\operatorname{VaR}\left(Y_{t}\right)^{2}+2 \rho\left(X_{t}, Y_{t}\right) \operatorname{VaR}\left(X_{t}\right) \operatorname{VaR}\left(Y_{t}\right)}
$$

dengan $\rho\left(X_{t}, Y_{t}\right)$ adalah korelasi antar peubah acak. Terdapat tiga korelasi yang biasa digunakan yaitu korelasi Pearson, Spearman Rho, dan Kendall Tau. Dalam artikel ini korelasi yang digunakan adalah korelasi Kendall Tau. Menurut Nelsen [10], Kendall Tau dapat diformulasikan sebagai berikut

$$
\rho_{\tau}\left(X_{t}, Y_{t}\right)=4 \int_{-\infty}^{\infty} \int_{-\infty}^{\infty} H(x, y) d H(x, y)-1
$$

$H(x, y)$ adalah fungsi distribusi bersama antar peubah acaknya. Namun tidak semua peubah acak memiliki fungsi distribusi bersama sehingga diperlukan alternatif lain untuk menentukan fungsi distribusi bersamanya yaitu dengan menggunakan Copula.

3.2. Agregat Value-at-Risk dengan Copula. Menurut Nelsen [11], Copula adalah suatu model multivariat yang berasal dari gabungan fungsi distribusi peubah-peubah acaknya dengan fungsi marginalnya berdistribusi Uniform $(0,1)$. Peubah acak yang digunakan adalah peubah acak risiko stokastik yang menyatakan besar klaim.

Teorema 3.1. Misalkan $X$ dan $Y$ adalah peubah acak dengan fungsi distribusi $F_{X}(x)$ dan $F_{Y}(y)$. Misalkan $H$ adalah fungsi distribusi bivariat maka akan terdapat Copula $C:[0,1]^{2} \rightarrow$ $[0,1]$ sehingga untuk setiap $x, y$ di $\mathbb{R}$ maka

$$
\begin{aligned}
H(x, y) & =C\left(F_{X}(x), F_{Y}(y)\right) \\
& =C(u, v)
\end{aligned}
$$

dengan $u=F_{X}(x)$ dan $v=F_{Y}(y)$. Sehingga berdasarkan Teorema 3.1 bahwa fungsi distribusi bersama dari peubah acak dapat dibentuk melalui model Copula. Akibatnya persamaan (5) dapat dituliskan sebagai berikut

$$
\begin{aligned}
\rho_{\tau}\left(X_{t}, Y_{t}\right) & =4 \int_{-\infty}^{\infty} \int_{-\infty}^{\infty} H(x, y) d H(x, y)-1 \\
& =4 \int_{0}^{1} \int_{0}^{1} C(u, v) d C(u, v)-1
\end{aligned}
$$

Menurut Ismail [6], peubah acak besar klaim biasanya mengikuti distribusi ekor tebal seperti Lognormal, Gamma, Weibull, dan Pareto. Keluarga Copula Archimedian cocok digunakan dalam mengkonstruksi sifat distribusi bersama untuk distribusi ekor tebal. Menurut Pellecchia [12], Copula Archimedian dibangun melalui fungsi generator. Misalkan $g$ adalah fungsi generator di mana $g(t)$ kontinu dan memiliki invers $g^{-1}$. Kemudian $g(t)$ adalah fungsi 
monoton tak turun dengan domain $[0,1]$ dan memenuhi $g(1)=0$. Copula Archimedian dapat dituliskan sebagai berikut

$$
C(u, v)=g^{-1}[g(u)+g(v)]
$$

Keluaga Copula Archimedian terdiri dari beberapa Copula antara lain Copula Clayton, Copula Frank, dan Copula Gumbel yang masing-masing memiliki fungsi generator.

(1) Copula Clayton

Fungsi generator dari Copula Clayton adalah $g(t)=\frac{t^{-\omega}-1}{\omega}$ dengan $\omega \in(0, \infty)$. Copula Clayton diformulasikan sebaai berikut

$$
C_{\text {Clayton }}(u, v ; \omega)=\left(u^{-\omega}+v^{-\omega}-1\right)^{-\frac{1}{\omega}}
$$

(2) Copula Frank

Fungsi generator dari Copula Frank adalah $g(t)=-\ln \left(\frac{-e^{\lambda t}-1}{e^{-\lambda}-1}\right)$ dengan $\lambda \in(-\infty, 0) \cup$ $(0, \infty)$. Copula Frank adalah sebagai berikut

$$
C_{\text {Frank }}(u, v ; \lambda)=-\frac{1}{\lambda} \ln \left(1+\frac{\left(1-e^{-\lambda u}\right)\left(1-e^{-\lambda v}\right)}{e^{-\lambda}-1}\right)
$$

(3) Copula Gumbel

Fungsi generator dari Copula Gumbel adalah $g(t)=(-\ln t)^{\delta}$ dengan $\delta \in[1, \infty)$. Copula Gumbel adalah sebagai berikut

$$
C_{\text {Gumbel }}(u, v ; \delta)=\exp \left(-\left[(-\ln u)^{\delta}+(-\ln v)^{\delta}\right]^{\frac{1}{\delta}}\right)
$$

Karena Copula yang digunakan berasal dari Copula Archimedian maka menurut Nelsen [11], korelasi Kendall Tau dapat dikonstruksi melalui fungsi generatornya. Sehingga persamaan (6) menjadi

$$
\rho_{\tau}\left(X_{t}, Y_{t}\right)=4 \int_{0}^{1} \frac{g(t)}{g^{\prime}(t)} d t+1
$$

Berikut adalah tabel hubungan fungsi generator pada keluarga Copula Archiedian dengan korelasi Kendall Tau

TABel 1. Fungsi generator dan Kendall Tau

\begin{tabular}{lcc}
\hline Copula & $g(t)$ & $\rho_{\tau}\left(X_{t}, Y_{t}\right)$ \\
\hline Clayton & $\frac{t^{-\omega}-1}{\omega}$ & $\frac{\omega}{\omega+2}$ \\
Frank & $-\ln \left(\frac{-e^{\lambda t}-1}{e^{-\lambda}-1}\right)$ & $1+\frac{4\left(D_{1}(\lambda)-1\right)}{\lambda}$ \\
Gumbel & $(-\ln t)^{\delta}$ & $\frac{\delta-1}{\delta}$ \\
\hline
\end{tabular}

dengan $D_{1}(\lambda)=\frac{1}{\lambda} \int_{0}^{\lambda} \frac{t}{e^{t}-1} d t$. Sehingga agregat VaR dengan menggunakan Copula dapat dituliskan sebagai berikut

$$
\operatorname{Ag}-\operatorname{VaR}_{1-\alpha}^{t+1}\left(S_{t}\right)=\sqrt{\operatorname{VaR}\left(X_{t}\right)^{2}+\operatorname{VaR}\left(Y_{t}\right)^{2}+2 \rho_{\tau}\left(X_{t}, Y_{t}\right) \operatorname{VaR}\left(X_{t}\right) \operatorname{VaR}\left(Y_{t}\right)}
$$

\section{Prediksi Agregat VaR pada Model Klaim ACA $(1,1)$}

Data risiko yang digunakan pada artikel ini adalah data pembayaran klaim dari perusahaan Danish Insurance (dalam satuan 1 Milyar Danish Krone). Risiko pertama berasal dari pembayaran klaim akibat rusaknya bangunan. Kemudian risiko kedua berasal dari pembayaran klaim akibat rusaknya peralatan yang ada dalam bangunan tersebut. Diasumsikan besar klaim dimodelkan menggunakan model ACA(1,1) dengan inovasi berdistribusi Weibull. Berdasarkan data yang ada maka didapatkan estimasi parameter $\mathrm{ACA}(1,1)$ untuk masing-masing besar klaim sebagai berikut 
TABEL 2. Penaksiran parameter model $\operatorname{ACA}(1,1)$

\begin{tabular}{lcc}
\hline Parameter & Klaim Bangunan & Klaim Peralatan \\
\hline$\widehat{\gamma}_{0}$ & 0.1809 & 0.9414 \\
$\widehat{\gamma}_{1}$ & 0.0152 & 0.0263 \\
$\widehat{\theta}_{1}$ & 0.9161 & 0.3382 \\
$\widehat{\beta}$ & 1.1022 & 0.6573 \\
\hline
\end{tabular}

Berdasarkan Tabel 2, angka-angka yang didapat merupakan estimasi parameter dari data yang ada. Parameter tersebut digunakan untuk memodelkan besar klaim yang akan datang sehingga perusahaan dapat memprediksi Value-at-Risk (VaR) untuk besar klaim tiap risiko. Kemudian, menggunakan formula agregat VaR dengan memanfaatkan VaR untuk masing-masing risiko dan korelasi Kendall Tau maka didapatkan hasil sebagai berikut

TABEL 3. Prediksi VaR risiko agregat ACA (1,1) dengan Kendall Tau

\begin{tabular}{|c|c|c|c|c|c|}
\hline Copula & Parameter & $\rho_{\tau}\left(X_{t}, Y_{t}\right)$ & $\widehat{A g-V a R}_{0.95}^{t+1}\left(S_{t}^{*}\right)$ & $\widehat{A g-V a R}_{0.97}^{t+1}\left(S_{t}^{*}\right)$ & $\widehat{A g-V a R}_{0.99}^{t+1}\left(S_{t}^{*}\right)$ \\
\hline Clayton & $\widehat{\omega}=0.8785$ & 0.3052 & 14.5416 & 17.9498 & 26.0578 \\
\hline Frank & $\widehat{\lambda}=3.1375$ & 0.3191 & 14.6122 & 18.0338 & 26.1702 \\
\hline \multirow[t]{3}{*}{ Gumbel } & $\widehat{\delta}=1.0090$ & 0.1528 & 13.0171 & 17.0017 & 24.7922 \\
\hline & & & & Correct VaR & \\
\hline & & & 0.95 & 0.97 & 0.99 \\
\hline Clayton & & & 0.9616 & 0.9702 & 0.9911 \\
\hline Frank & & & 0.9616 & 0.9702 & 0.9911 \\
\hline Gumbel & & & 0.9553 & 0.9672 & 0.9873 \\
\hline
\end{tabular}
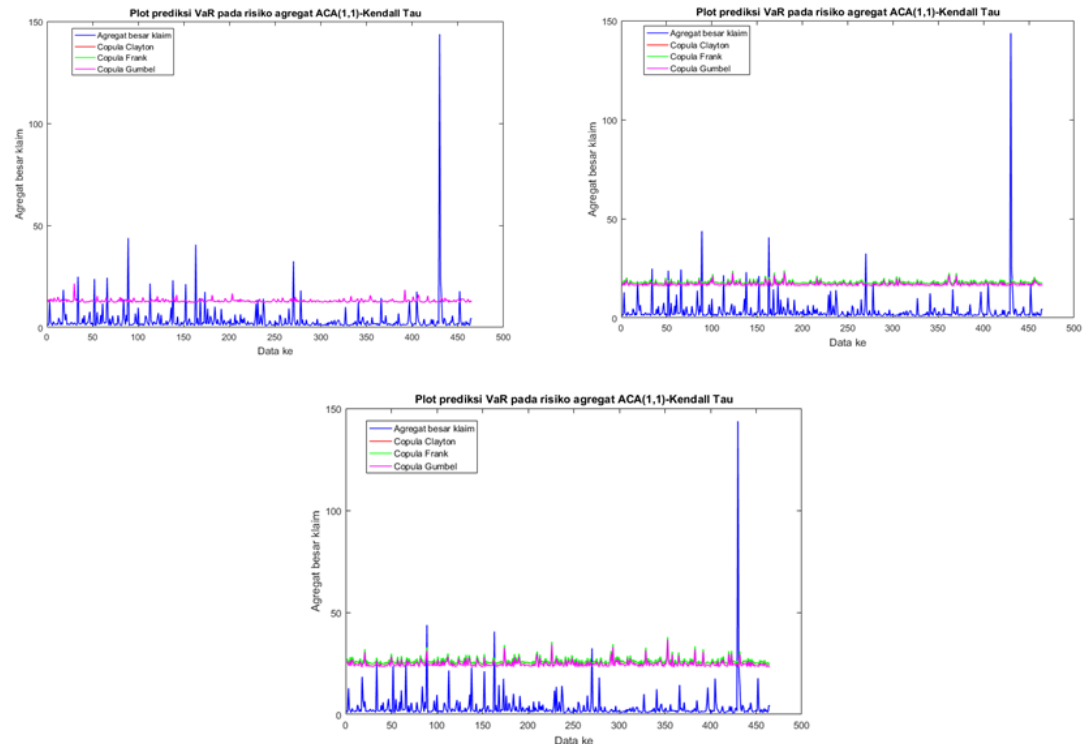

GAMBAR 1. Grafik prediksi VaR risiko agregat besar klaim dengan kendall tau pada berbagai tingkat kepercayaan 0.95 (kiri atas), 0.97 (kanan atas), 0.99 (bawah) 
Berdasarkan Tabel 3, terdapat tiga jenis Copula yaitu Clayton, Frank, dan Gumbel yang digunakan untuk memodelkan kebergantungan antar besar klaim. Didapatkan parameter Copula Clayton $\widehat{\omega}=0.8785$, Copula Frank $\widehat{\lambda}=3.1375$, dan Copula Gumbel $\widehat{\delta}=1.0090$. Parameter Copula tersebut digunakan untuk menentukan ukuran kebergantungan Kendall Tau. Selanjutnya dengan memanfaatkan nilai Kendall Tau maka didapatkan hasil agregat VaR dengan Copula Clayton, Copula Frank, dan Copula Gumbel masing-masing adalah 14.5416, 14.6122, dan 13.0171 pada tingkat kepercayaan 0.95. Pada tingkat kepercayaan 0.97 dan 0.99, nilai agregat VaR akan semakin membesar. Hal ini berarti semakin besar tingkat kepercayaan yang dipilih maka perusahaan akan lebih banyak menanggung besar klaim. Kemudian berdasarkan Gambar 1, garis horizontal menggambarkan nilai agregat VaR untuk tiap Copula dan garis biru menggambarkan besar agregat klaim. Nilai-nilai dibawah garis horizontal adalah nilai besar klaim yang dapat ditanggung oleh perusahaan sedangkan nilai diatas garis horizontal merupakan nilai yang akan ditanggung oleh pihak lain misalnya reasuransi.

\section{Simpulan}

Dalam artikel ini, risiko agregat yang terbentuk berasal dari dua besar klaim yang saling bergantung. Besar klaim tersebut masing-masing dimodelkan melalui model ACA(1,1). Kemudian kebergantungan antar besar klaim direpresentasikan melalui kombinasi Kendall Tau dengan konsep Copula. Risiko agregat tersebut diukur risikonya melalui prediksi VaR dengan tingkat kepercayaan 0.95, 0.97, dan 0.99. Tingkat kepercayaan ini mempengaruhi prediksi besar klaim yang akan datang. Jika dilihat dari sisi perusahaan asuransi, perusahaan lebih baik memilih prediksi pada tingkat kepercayaan 0.95 sehingga nilai prediksi VaRnya kecil yakni 14.5416, 14.6122, dan 13.0171 untuk masing-masing Copula Clayton, Copula Frank, dan Copula Gumbel. Kemudian berdasarkan kecocokan modelnya melalui Correct VaR maka pada artikel ini model ACA(1,1) dengan Copula Gumbel adalah model yang paling baik untuk memprediksi agregat VaR. Hasil Agregat VaR pada tingkat kepercayaan 0.95 dan Correct VaR nya masing-masing adalah 13.0171 dan 0.9553.

\section{DAFtar Pustaka}

[1] Abdal, A.M., 2017, Ukuran Prediksi Risiko Tail-Value-at-Risk (TVAR) pada Model Agregat Risiko. Tesis Program Magister, Institut Teknologi Bandung.

[2] Araichi, S., Perreti, C., Belkacem, L., 2015, Generalized Autogressive Conditional Sinistrality Model : A Novel Model For Claims Reserving in Non Life Insurance, Laboratoire De Sciences Actuarielle et Financiere, Universite Lyon.

[3] Araichi, S., Perreti, C., Belkacem, L., 2016, Solvency Capital Requirement for Temporal Dependent Losses in Insurance, Economic Modelling, 58, pp 588-598.

[4] Corrigan, J., Jethro, D.D., Takanori, H., Lotte, V.D., Henny, V., 2009, Aggregation of Risks and Allocation of Capital, Miliman Reasearch Report.

[5] Dowd, K., 1998, Beyond Value-at-Risk : The New Science of Risk Management, John Wiley and Sons Ltd, England.

[6] Ismail, I., 2018, Dependence Structures and Risk Aggregation using Copulas. Doctor Thesis, Univesity of Leicester.

[7] Iqbal, S., Choudhry, R.M., Holschemacher, K., Ali, A., Tamosaitiene, J., 2015, Risk Management in Construction Projects, Technological and Economic Development of Economy, 21:1, pp 65-78.

[8] Klugman, S.A., Panjer, H.H., Willmot, G.E., 2012, Loss Model : From Data to Decisions, Fourth Edition, John Wiley and Sons, United States of America.

[9] Li, J., Zhu, X., Lee, C.F., Wu, D., Feng J., Shi, Y., 2015, On The Aggregation of Credit, Market, and Operational, Review of Quantitative Finance and Accounting, 44, pp 161-189.

[10] McNeil, A.J., Frey, R., Embrechts, P., 2005, Quantitative Risk Management: Concepts, Techniques and Tools,Princeton University Press. United States of America.

[11] Nelsen, R.B., 2006, An Introduction to Copulas, Springer Science + Bussiness Media. United States of America. 
[12] Pellecchia, M., Perciaccante, G., 2019, The Calculation of Solvency Requirement using Copulas, https://mpra.ub.uni-muenchen.de/94213/MPRA Paper No. 94213, on June 28, 2019.

[13] Rohmawati, A.A., Syuhada, K.I.A., 2015, Value-at-Risk and Expected Shortfall Relationship, International Journal of Applied Mathematics and Statistics, 53, pp 200-205.

[14] Vender, M., 2014, Risk Aggregation and Capital Allocation using Copula. Magister Thesis, North-West University.

[15] Wong, Z.Y., Chin, W.C., Tan, S.W., 2016, Daily Value-at-Risk Modelling and Forecast Evaluation : The Realized Volatility Approach, The Journal of Finance and Data Science, 2, pp 171-187. 
138 Prihandoko dkk, JMI Vol 15(2) Okt 2019, pp. 129-137,doi:10.24198/jmi.v15.n2.23443.129-137 